\title{
MediData: the growing physician workforce
}

$\mathrm{T}$

he number of physicians in Canada increased from 68101 in 2009 to 77674 in 2013, outpacing population growth by a factor of three, according to a new report from the Canadian Institute for Health Information. There is a fairly even split between family doctors (39 392) and specialists (38 282). For every 100000 Canadians in 2013, there were 220 physicians. To put this into perspective, there were 280 doctors per 100000 residents in the United Kingdom in 2012, and 250 per 100000 in the United States the year before, according to the World Health Organization.

Percentage-wise, Saskatchewan had the most new physicians (351), an increase of $20.6 \%$. That province's population has increased by more than 100000 in the past six years and is historically underserviced. All provinces experienced double-digit growth except British Columbia, where the number of doctors increased by only $8.6 \%$. The territories, which have few physicians, saw either no growth or negative growth.

Though total payments to physicans again increased, by $3.5 \%$ in $2012-13$ to $\$ 22.8$ billion, the increase was the lowest in a decade. On average, physicians grossed the most annually in Ontario (\$370 731) and the least in Nova Scotia (\$261 422). The average gross clinical payment across Canada increased by less than \$1000 in 2011-12 over the previous year.

Other highlights from the report:

- The number of female physicians increased by $22.5 \%$ between 2009 and 2013, while the number of the male physicians increased by only $9.2 \%$.

- Female doctors account for $43.1 \%$ of family physicians and $33.2 \%$ of specialists.

- Overall fee-for-service payments in 2012-13 came to $\$ 14.6$ billion, with an average fee for service of $\$ 43.35$ for family doctors and $\$ 77.69$ for specialists. — Roger Collier, CMAJ

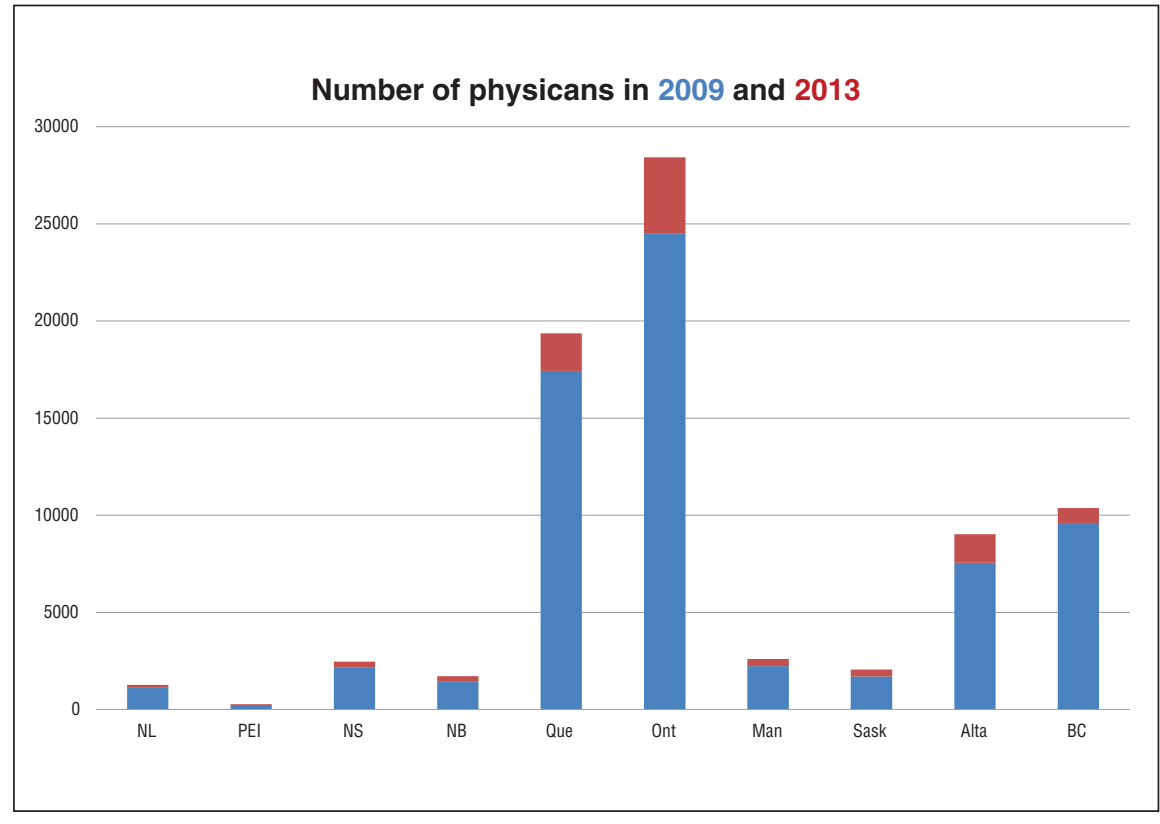

\section{Average gross clinical payment}
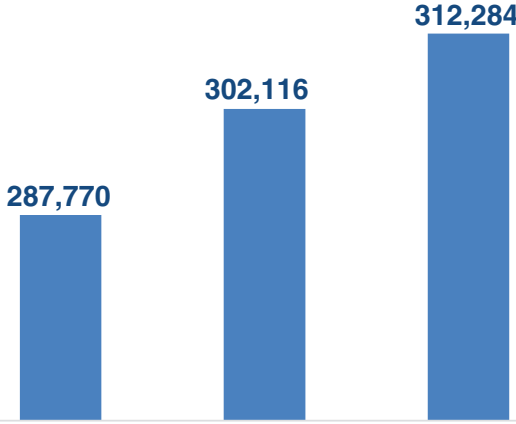

200809

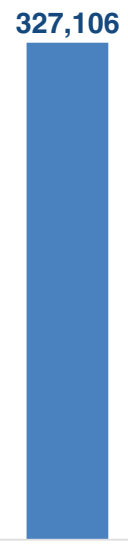

201112
328,067

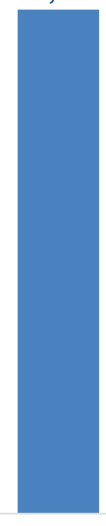

201213 